\title{
Rainfall Trends, Drought Frequency and La Niña in Tuvalu: A Small Equatorial Island State in the Pacific Ocean
}

\author{
Luke Paeniu*, Elisabeth Holland, Cara Miller and Giulia Anderson \\ Department of Climate Change, University of the South Pacific (USP), Laucala campus, Suva, Fiji
}

\begin{abstract}
Droughts, as complex climatic hazards, can threaten livelihoods, economies, and ecosystems in low-lying island states. In extreme cases, drought may cripple national development in these countries, and produce long-term impacts that hinder national efforts to achieve the United Nations' sustainable development goals. This study addresses rainfall trends, the frequency of droughts, La Niña influences and the relationship between rainfall and Sea Surface Temperature (SST) in the small Pacific country of Tuvalu. The study follows this order of approach: (1) examine observed rainfall time series for four meteorological stations across Tuvalu; (2) decompose observed rainfall time series and develop detrended rainfall time series; (3) evaluate and identify rainfall trends, including drought frequency; (4) define drought in Tuvalu using box plots; (5) evaluate the seasonal cycle of rainfall; (6) identify La Niña years and (7) test the correlation between SST, an indicator of La Niña events, and rainfall. The findings of this study revealed that (1) de-trended rainfall time series show declining trends in all four rainfall stations over the period 1953-2012; (2) the frequency of drought ranges from three to fourteen years with a mean of nine years; (3) the occurrence of drought appears to follow the La Niña years; (4) boxplots provide an effective option for defining drought and, finally, (5) there is empirical support for a moderate to strong correlation between the de-trended values of SST and rainfall in the area of study.
\end{abstract}

Keywords: Drought; Rainfall; De-trended rainfall; Seasonal cycle; La Niña; Sea surface temperature

\section{Introduction}

Drought is a complex climate phenomenon $[1,2]$ that can threaten ecosystems, economies, and people's livelihoods. It can affect almost all sectors of society and can hinder sustainable development in vulnerable nations, such as small Pacific Island Countries (PICs). Severe drought may cripple economies [3]. The complexities of drought are attributed to its slow creeping nature [4]; the difficulties in defining and quantifying it [5]; and the impacts that it has on the hydrological cycle, ecosystems, and various sectors of society and individual livelihoods [2]. This study addresses rainfall trends, drought frequency, La Niña and the relationship between rainfall and sea surface temperature in Tuvalu, a small island state within the equatorial Pacific Ocean. It is located between latitude $5^{\circ}-11^{\circ}$ South and longitude $176^{\circ}-180^{\circ}$ East (see Figure 1). The nation consists of nine scatters islands namely: Nanumea, Nanumaga, Niutao, Nui, Vaitupu, Nukufetau, Funafuti, Nukulaelae and Niulakita. All of these islands lack quality groundwater resources, and instead rely on rain for drinking and food preparation. Rainfall in Tuvalu is quite high, as documented in some literature. However, in some cases, Tuvalu experiences dry spells or droughts. The key objectives of this study were to document rainfall time series for four islands equipped with rainfall stations (Nanumea, Nui, Funafuti and Niulakita); to abstract rainfall trend values by decomposing each rainfall time series; to identify drought frequencies by calculating a threshold value that defines drought events and applying it to historical rainfall data; to identify La Niña years by using SST; to define drought in Tuvalu using box plot models; and to test the correlation between SST and rainfall.

Drought in Tuvalu has been documented in past studies by the Doberitz et al. [6,7] followed by Thompson et al. [8-14] and most recently by the [15]. Bardsley and Vavae found that SST in the Nino 4 region can anticipate dry periods, but their study was limited to rainfall data from Funafuti, and relationship analysis through scatterplots. Thompson analysed rainfall for all islands of Tuvalu for a period of 40 years, from
1951-1980. He found that dry periods in Tuvalu are associated with positive SOI. He documented severe drought periods ranging from one to four months at different time periods for the different islands. However, historical droughts were not covered in detail in these past studies.

\section{Methods}

\section{Data Sources}

Based on the assessment of the relationship between various climatological measurements and the low-rainfall conditions, the key variables used in this study were observed rainfall and observed SST taken from Nino 3.4. Rainfall data were obtained from the Tuvalu Meteorological Station, while SST was retrieved from NOAA's website: (http://www.esrl.noaa.gov/psd/gcos_wgsp/Timeseries/Data/nino34. long.data). The other important variables that were used in this study were ONI and MEI data. These were retrieved from (http://www.esrl. noaa.gov/psd/data/correlation/oni.data) and (http://www.esrl.noaa. gov/psd/data/correlation/mei.data).

\section{Study area}

The four rainfall stations in Tuvalu that were used in this study were Nanumea, Nui, Funafuti and Niulakita. The map of rainfall stations was designed using Google Earth and QGIS software. These rainfall stations are presented in Figure 1.

*Corresponding author: Luke Paeniu, Department of Climate Change, University of the South Pacific (USP), Laucala campus, Suva, Fiji, Tel: +6793231000; E-mail: sweetmemory7@yahoo.com (or) luke.paeniu@usp.ac.fj

Received August 26, 2017; Accepted September 03, 2017; Published September 07, 2017

Citation: Paeniu L, Holland E, Miller C, Anderson G (2017) Rainfall Trends, Drough Frequency and La Niña in Tuvalu: A Small Equatorial Island State in the Pacific Ocean. J Environ Anal Toxicol 7: 501. doi: 10.4172/2161-0525.1000501

Copyright: $\odot 2017$ Paeniu L, et al. This is an open-access article distributed under the terms of the Creative Commons Attribution License, which permits unrestricted use, distribution, and reproduction in any medium, provided the original author and source are credited. 
Citation: Paeniu L, Holland E, Miller C, Anderson G (2017) Rainfall Trends, Drought Frequency and La Niña in Tuvalu: A Small Equatorial Island State in the Pacific Ocean. J Environ Anal Toxicol 7: 501. doi: 10.4172/2161-0525.1000501

Page 2 of 7

Map of Tuvalu Rainfall Stations

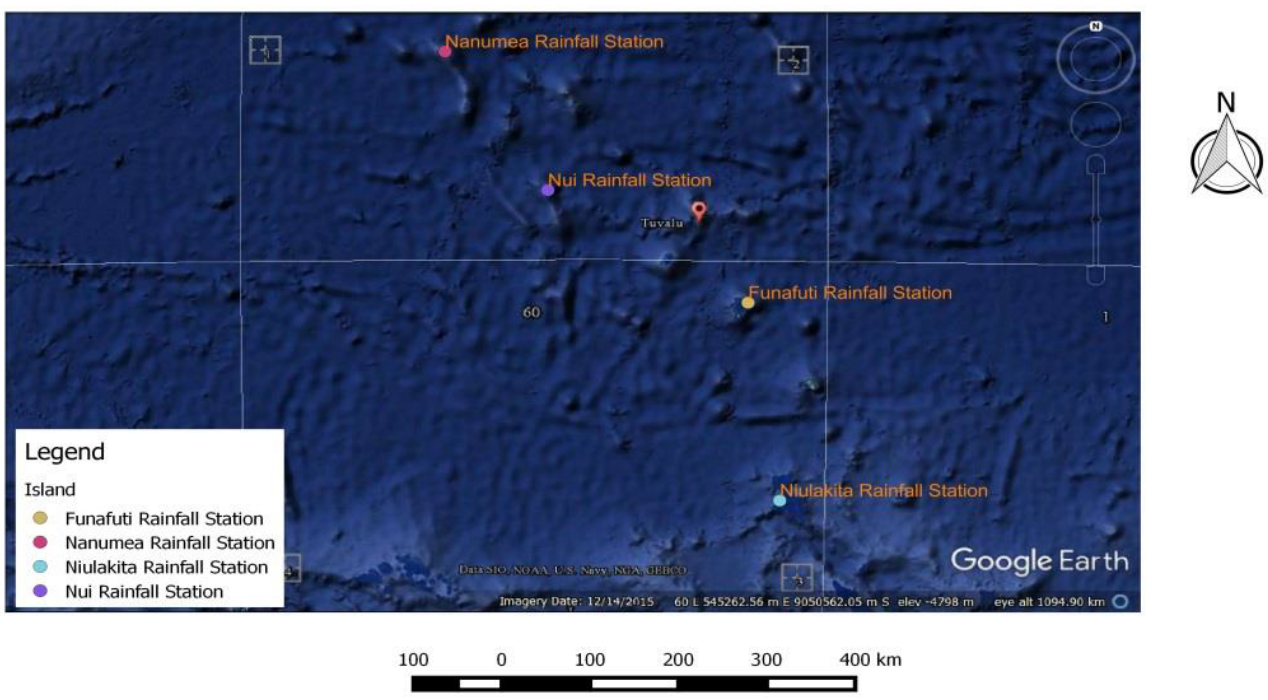

Figure 1: Locations of rainfall stations in Tuvalu.

\section{Data manipulation}

The approach used in this study begins with the collection of data, followed by a review of past studies, the organisation of data into csv files for processing in $\mathrm{R}$ studio, submission to time series analysis, decomposition of time series, design of de-trended time series and boxplots, evaluation of seasonal cycles, identification of La Niña years using ONI, MEI and Nino 3.4 SST, and the tests for correlations between SST and rainfall.

\section{Statistical analysis}

This study uses computer programs including R-Studio and Microsoft Excel to conduct basic analysis. After data collection, the resulting datasets were sorted and organised into proper excel spreadsheets for R-Studio to accept. Rainfall time series and decomposition of time series were analysed using R-Studio to show rainfall trends, seasonal cycles and residual effects. Statistical hypotheses were tested using the Pearson method. Correlation tests between SST and rainfall was conducted using R-Studio.

\section{Limitations of the study}

This study examines rainfall and Nino indices and ENSO but does not examine other climate predictors such as trade winds, SPCZ and warm water volume (WWV). The period of rainfall observation was limited to 1953-2012 as the data common to all four rainfall stations was available for this period.

\section{Hypothesis}

The null hypothesis $\left(\mathrm{H}_{0}\right)$ assumes that there is no statistical significant difference between the two variables (rainfall and SST) in the region under study. The alternate hypothesis $\left(\mathrm{H}_{1}\right)$ therefore assumes that there is a statistically significant difference between the two variables. In order to reject the null hypothesis, p-value must be equal to 0.05 , however if it is less than 0.05 , then there is not enough evidence to reject the null hypothesis.

\section{Results}

Between 1953 and 2012, rainfall declined in Tuvalu by an average of $0.5 \mathrm{~mm}$ per decade with noticeable significant declines for all four stations: Nanumea, Nui, Funafuti, and Niulakita (Figure 2). Both the monthly average rainfall analyses and the deseasonalised trends (Figure 3) showed statistically significant declines in rainfall for all stations. A few researchers have attempted to define drought for Tuvalu in the past, and this study contributes to this trend by adding an option of using a box plot model. Drought can be defined as times when de-trended rainfall falls below $25 \%$ of the median level, or reaching the first quartile level. Extreme drought can be regarded as $40 \%$ below the median level, or beyond the lower whisker.

The seasonal cycles and residual 'noise level' in a rainfall time series were removed by performing a seasonal decomposition in R Studio. The output produced by R-Studio (Figure 4) consists of four rows. The first row in each of the four figures illustrates the observed monthly rainfall time series. The second row displays the normal seasonal cycle pattern. The bottom row is the residual effect. If all the three noise levels are taken out of the time series, the third row, outlined in red, is what is left. This is the exact trend of the rainfall time series, which will be referenced in future as de-trended values.

Taking the average of all the four rainfall stations, a declining trend is also confirmed (see Figure 5 with a slope of $-3.0 \mathrm{~mm}$ over six decades and a p-value of $9.98^{-14}$ ).

No previous studies have been able to illustrate the declining rainfall trend observed in Figure 5 with the level of clarity and empirical support provided in this research. The causes of this declining trend are unknown and may form the basis of future scientific research. Future research may determine if either climate change or the influences of ENSO are likely to be the key causes of the declining rainfall.

Within the period of observation of 1953-2012, eight strong historical drought years were observed in Tuvalu. These drought years were exhibited clearly in the calculation of the average de-trended rainfall values for all four rainfall stations. These historical drought 
Citation: Paeniu L, Holland E, Miller C, Anderson G (2017) Rainfall Trends, Drought Frequency and La Niña in Tuvalu: A Small Equatorial Island State in the Pacific Ocean. J Environ Anal Toxicol 7: 501. doi: 10.4172/2161-0525.1000501
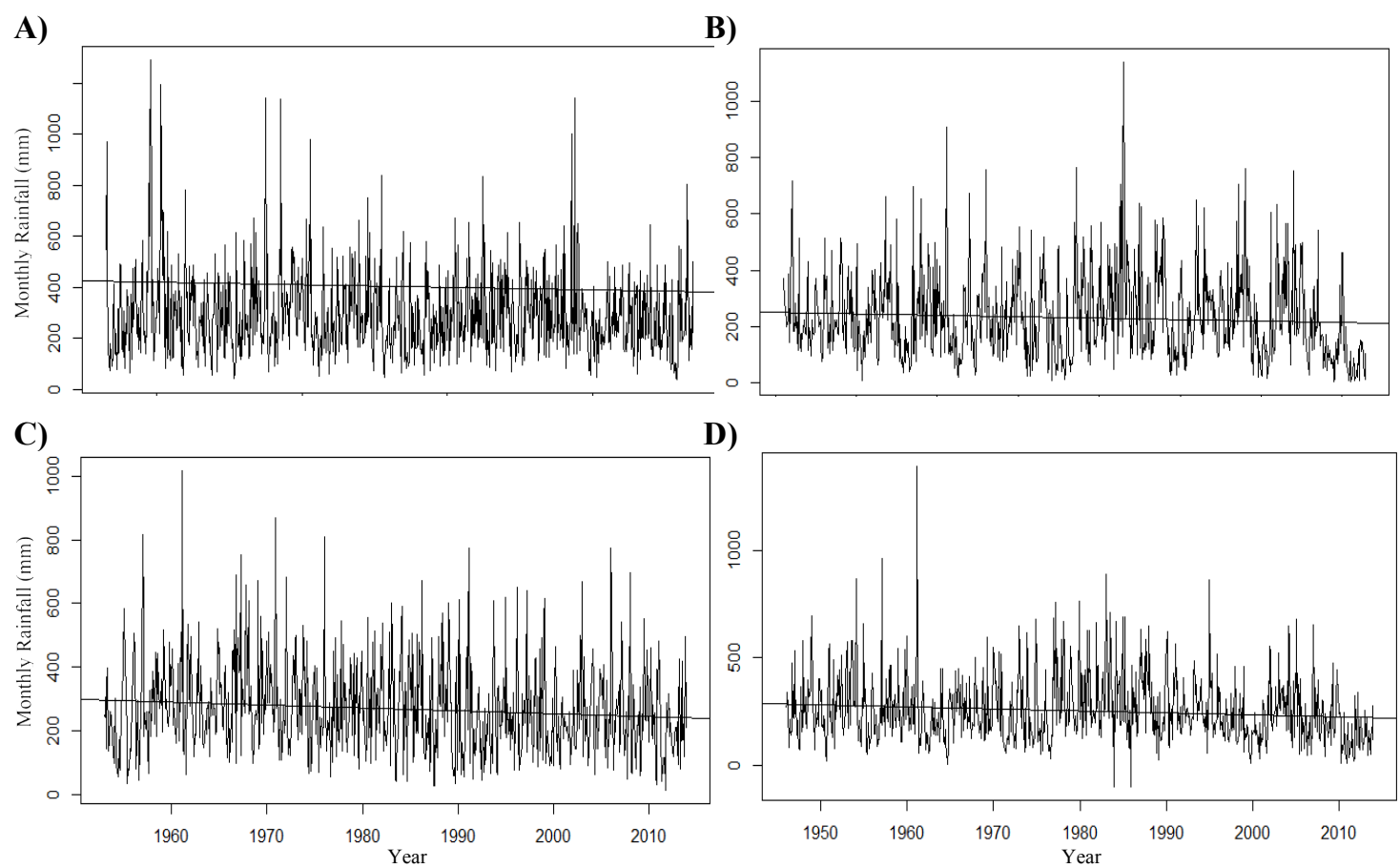

Figure 2: Observed monthly rainfall time series for A) Funafuti, B) Nanumea, C) Niulakita, and D) Nui.

A)

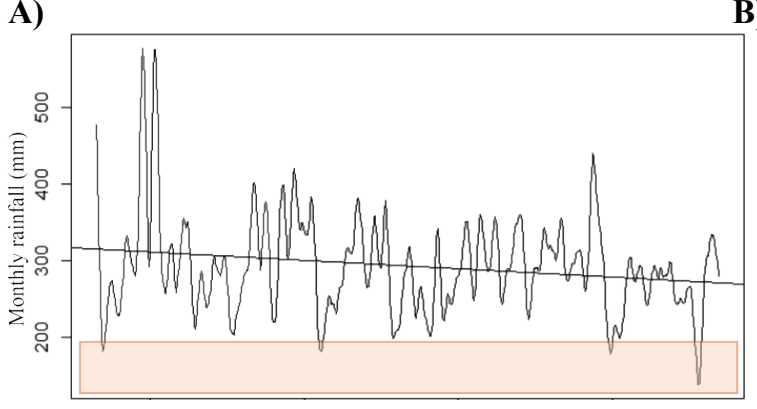

C)

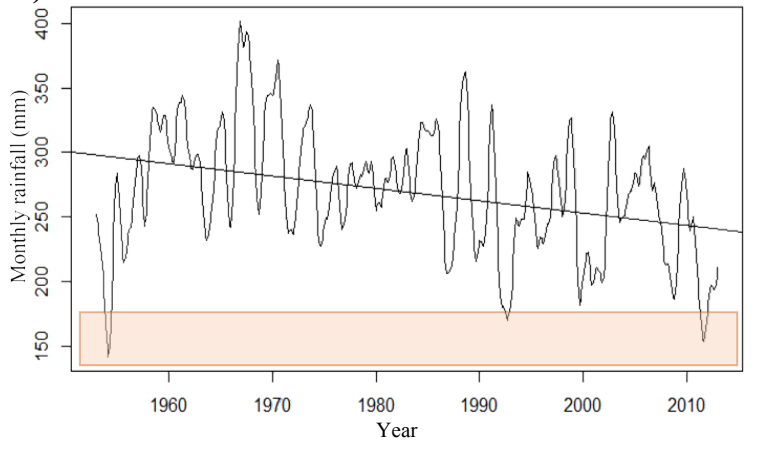

B)

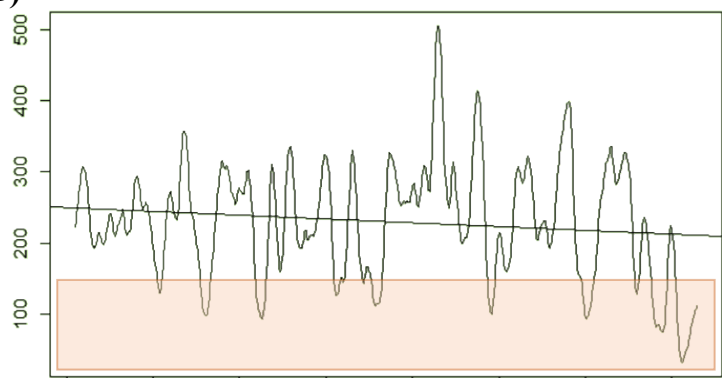

D)

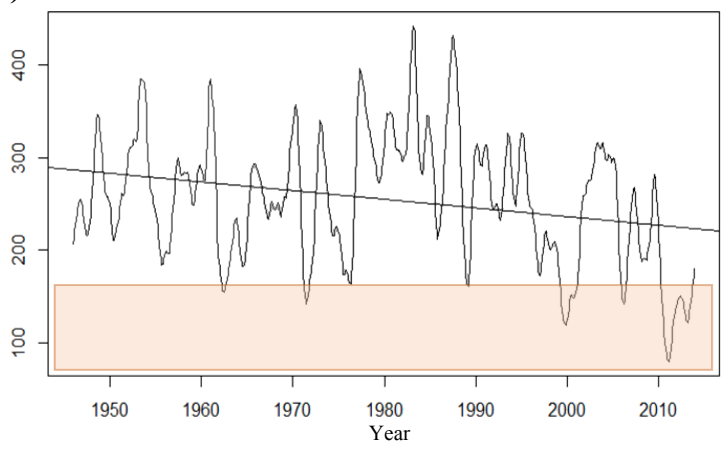

Figure 3: De-trended rainfall time series for A) Funafuti, B) Nanumea, C) Niulakita, and D) Nui. Drought conditions are marked by the colored boxes, and are defined as $193.3 \mathrm{~mm}$ of rainfall per month in Funafuti, $149.5 \mathrm{~mm}$ in Nanumea, $182.25 \mathrm{~mm}$ in Niulakita, and $167.55 \mathrm{~mm}$ in Nui, as determined by boxplot analyses.

years were in 1955-56, 1962, 1971-72, 1975-76, 1989, 1999-01, 200709 and 2010-12, and are identified by red arrows in Figure 6 above. The lowest troughs in the figure relate directly to extreme historical droughts in Tuvalu. This finding is new and will be useful in improving our understanding of historical droughts in Tuvalu.
The frequency of droughts in Tuvalu, based on the calculation presented in Figure 6, varies considerably. Given the period of observation, the length of time between each drought ranges from three to fourteen years, with a mean time of nine years. It took seven years from the first drought in 1955-56, for the second one to emerge. 
Citation: Paeniu L, Holland E, Miller C, Anderson G (2017) Rainfall Trends, Drought Frequency and La Niña in Tuvalu: A Small Equatorial Island State in the Pacific Ocean. J Environ Anal Toxicol 7: 501. doi: 10.4172/2161-0525.1000501

A)

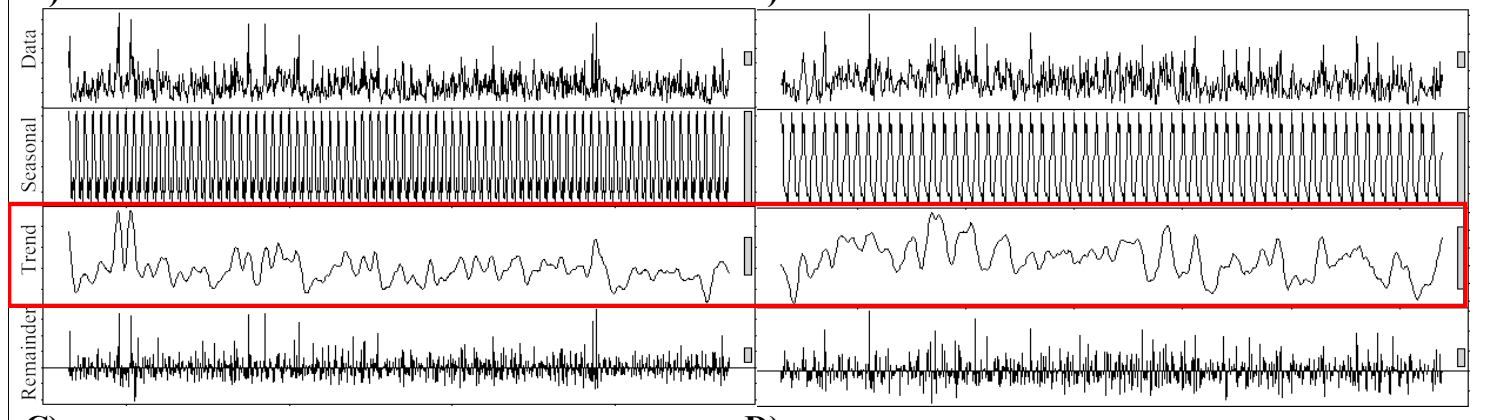

C)

B)
C)

D)

\section{口.}

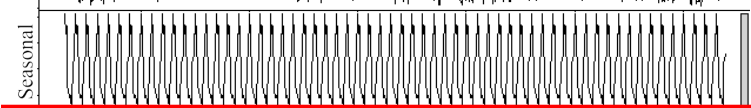

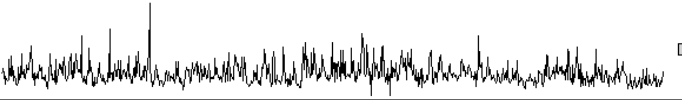
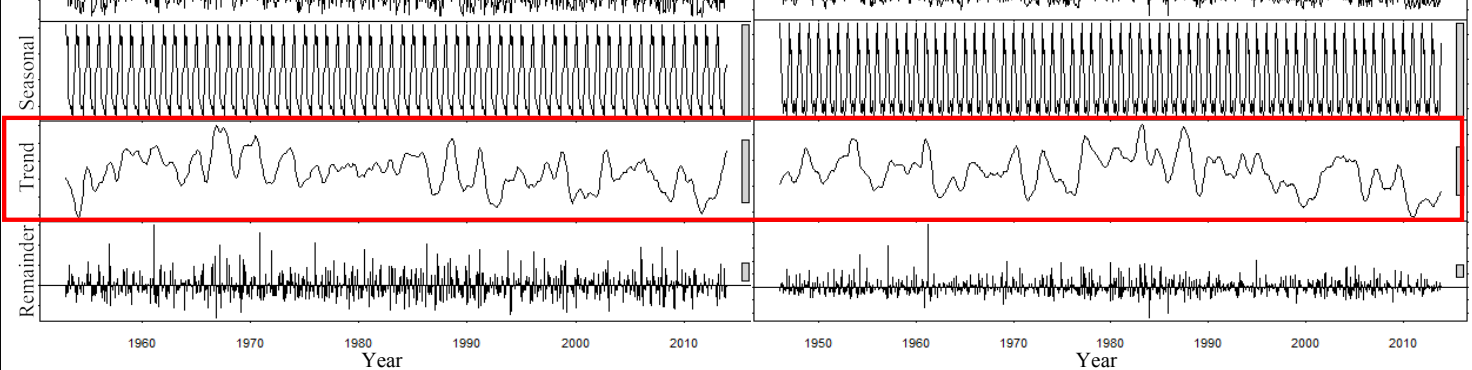

Figure 4: Decomposed rainfall time series for A) Funafuti, B) Nanumea, C) Niulakita, and D) Nui stations. Top row represents observed rainfall data. Second from the top row represents seasonal rainfall data. Third row represents rainfall trend data. The bottom row represents the remaining part of rainfall data.

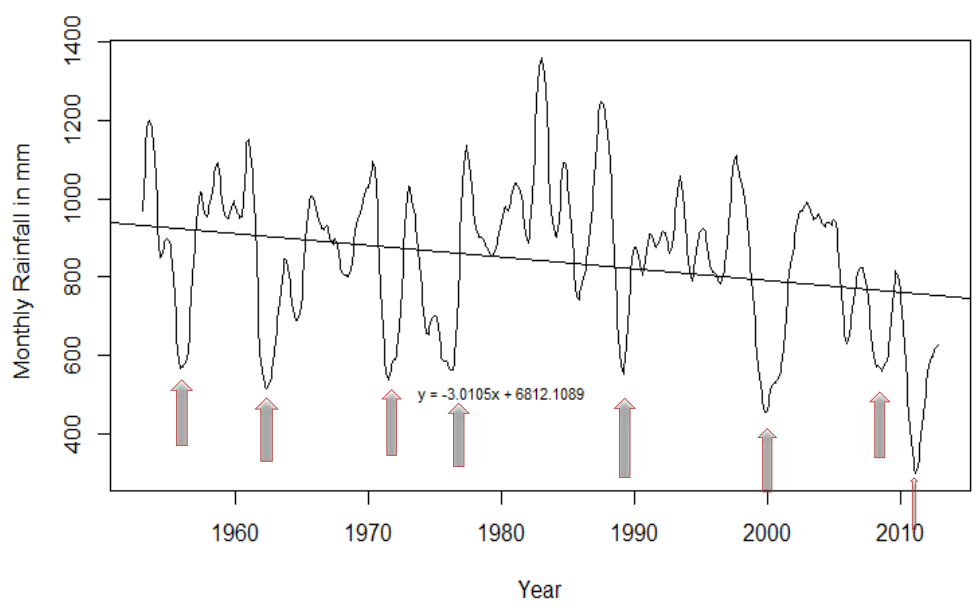

Figure 5: All Four Decomposed Rainfall Stations Time Series 1953-2012. The red arrows indicate drought.

The third extreme drought happened nine years later in 1971-72, but the fourth took only four years to observe extreme drought again in 1975-76. It took 14 years for the 1989 drought to occur. Ten years later the 1999-01 extreme drought occurred. There were eight years before the 2007-09 drought occurred, and finally three years until the 2010-12 drought struck the nation. Furthermore, each drought differs in terms of intensity, duration and onset. The next general finding shows that the frequency of extreme drought in Tuvalu cannot be determined by simple linear algebra. Alternatively, there is a high possibility that the frequency of drought is linked with the influence of La Niña that normally occurs between 2-7 years. The only exception was the 1962 drought, which occurred during an ENSO neutral year.
La Niña years can be estimated from various sources. The standard measurement of La Niña used by NOAA is the Oceanic Nino Index [16], which declares a La Niña event if a 3 month running mean of ERRST.v3b SST data remains below a threshold of $0.5^{\circ} \mathrm{C}$ below the 30 year SST mean in the Nino 3.4 zone. The years that were related to La Niña using ONI calculations were as follows: 1950-51, 1954-1956, 1964, 1970-71, 1973-76, 1984-85, 1988-1989, 1998-2001,2007-2008, 2008-2009, 2010-2011 and 2011-2012. These dates correspond well with Tuvalu drought events (Figure 6).

The other way of identifying La Niña years is by looking at MEI time series (see Figure 7 below). MEI was developed primarily for research purposes [17]. It differs from ONI by incorporating more 
Citation: Paeniu L, Holland E, Miller C, Anderson G (2017) Rainfall Trends, Drought Frequency and La Niña in Tuvalu: A Small Equatorial Island State in the Pacific Ocean. J Environ Anal Toxicol 7: 501. doi: 10.4172/2161-0525.1000501

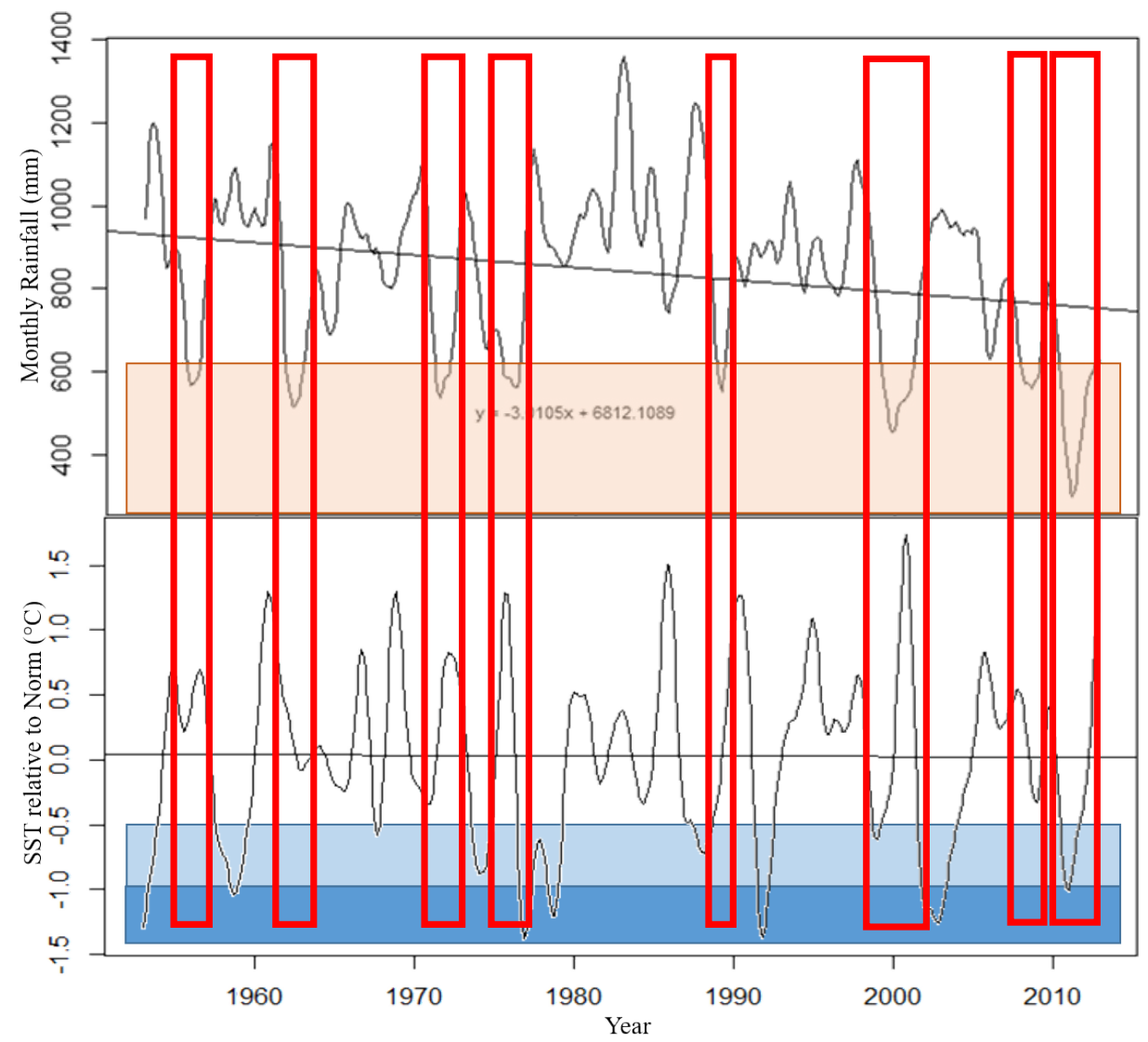

Figure 6: Comparison of Drought years (top graph, marked with red bars) with La Niña years (bottom graph, when SST(N3.4) crosses $-0.5^{\circ} \mathrm{C}$; strong La Niña events happen when the trend crosses -1.0 degrees $\mathrm{C}$ ).

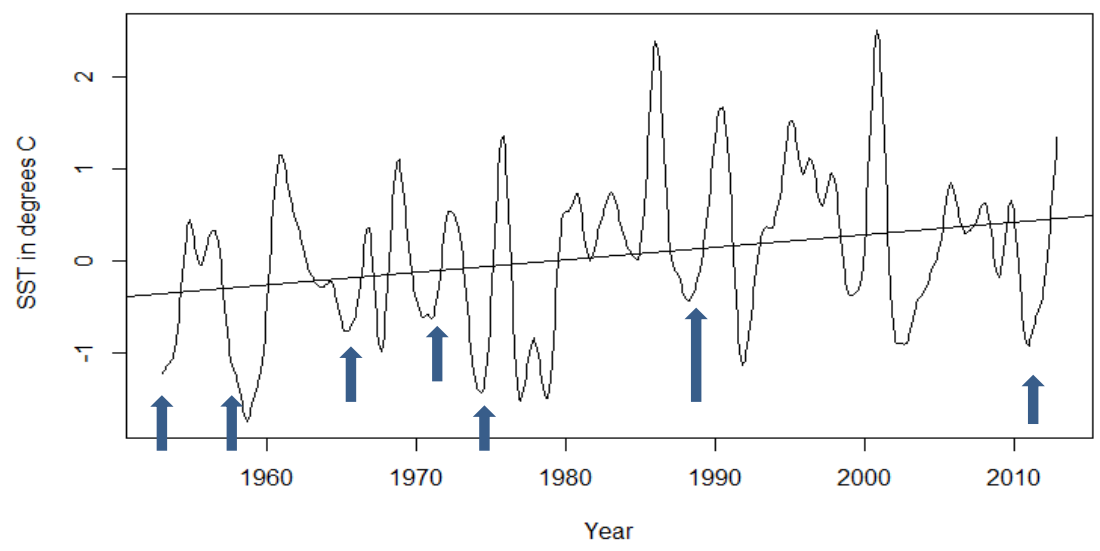

Figure 7: MEl time series 1953-2012. The blue arrows show La Niña years.

environmental variables in its calculation matrices, as opposed to using only SST. Negative values of MEI relate to La Niña phase, while positive values represent El Niño phase. The seven strong La Niña years identified under MEI since 1949 were 1949-51, 195456, 1964-66, 1970-72, 1973-75, 1988-90, and 2010-12 (Figure 8). La Niña events are declared when adjusted SST yearly averages are $0.5^{\circ} \mathrm{Centigrade}$ or more below the inter-annual average value. Coincidentally, the drought years appear to match the years when La Niña emerged.
Given that drought is a slow creeping climate phenomenon in which the onset and completion can only be confirmed well after the fact, defining drought is a complex task. The next finding reveals that boxplots are an optimal analysis tool for identifying drought conditions, and may be an option for use in defining drought. Drought can be defined as times when de-trended rainfall values fall below $25 \%$ of the median level, or reach the first quartile level. Extreme drought can be regarded as $40 \%$ below the median level or more. This can be visualised using the boxplot analysis (Figure 8 below). 


\section{Boxplots for Rainfall in Four stations in Tuvalu}

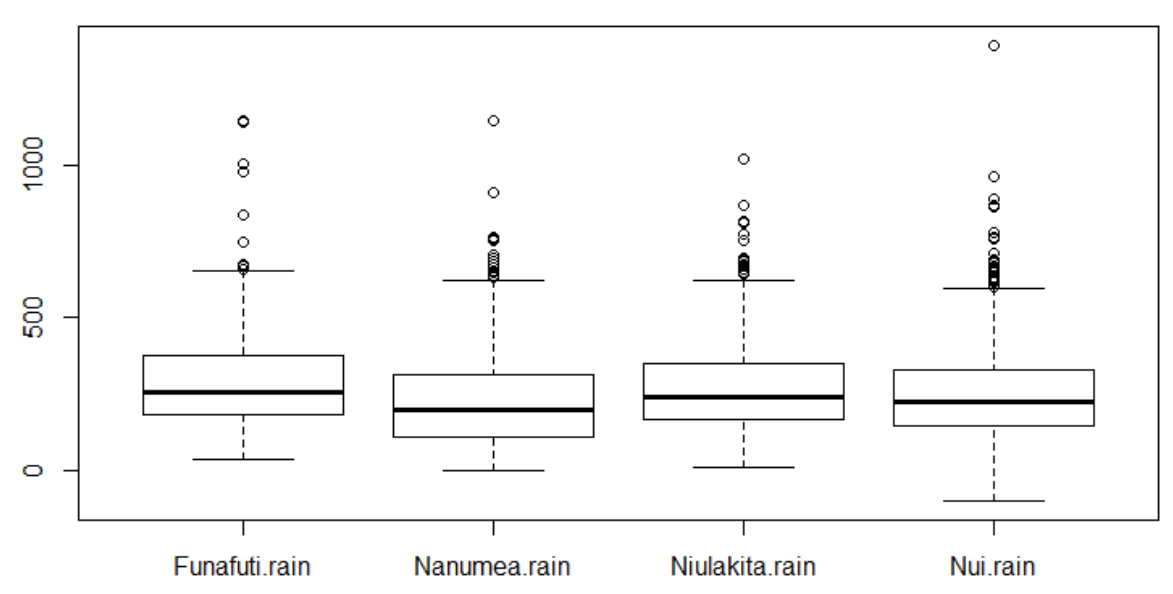

Figure 8: Boxplots of observed monthly rainfall of four stations 1953-2012.

Boxplots divide rainfall into quartiles and percentiles, in order to visualise how rainfall is distributed over the observed period. The low whisker $\left(2.5^{\text {th }}\right.$ percentile) marks the beginning of the first quartile, which includes the first to twenty-fifth percentile (the 25 th percentile is the bottom edge of the box). The box appears as a rectangle and covers the inter quartile range (IQR) which, represents the $50 \%$ percentile, the median, and the $75 \%$ percentile at the top edge of the box. The upper whisker is the $97.5 \%$ percentile. Beyond the low and upper whiskers are the outliers. The long term median, calculated over a sixty year period from 1953-2012, is revealed through the thick black line in each box. A dry period can be defined as a year when rainfall falls below the median. The farther below the median a rainfall value falls, the more intense the dry period it describes. Rainfall recorded above the median can be regarded as above normal rainfall. The low and upper whiskers $\left(2.5^{\text {th }}\right.$ percentile and 97.5 percentile $)$ are extreme cases. Beyond these whiskers are the outliers, which represent extreme cases of rainfall anomalies. All of the outliers for the four stations are situations of excessive rainfall, as they fall well beyond the upper whisker level.

The study constructed boxplots for each of the four stations to improve our knowledge of distribution and variability of rainfall across the nation for period 1983-2012. It should be noted that the use of percentiles, rather than absolute volumes of rainfall, allows for local variation in the different stations. As part of this condition, the four stations have different medians. Funafuti has a monthly median rainfall of $257.8 \mathrm{~mm}$, compared to $199.0 \mathrm{~mm}$ in Nanumea, $243.0 \mathrm{~mm}$ in Niulakita, and $223.4 \mathrm{~mm}$ in Nui. Drought for these stations can be defined using the $25 \%$ calculations as Nanumea rainfall equal or less than $149.5 \mathrm{~mm}$, Nui rainfall equal or less than $167.5 \mathrm{~mm}$, Funafuti rainfall equal or less than $193.3 \mathrm{~mm}$ and Niulakita rainfall equal or less than $182.2 \mathrm{~mm}$.

The study revealed that the rainfall seasonal cycle was identical on a year to year basis. The positive rainfall values begin in December and end in March. Likewise, negative rainfall values begin in April and end in November. The cycle relates closely with the two distinct seasons in Tuvalu: the wet and dry seasons.

The final finding relates to testing of the hypothesis. The study confirmed that the correlation between de-trended rainfalls and detrended SST is statistically significant for the period of observation.
When SST is negative, this corresponds with below normal rainfall which in turn corresponds to La Niña. The correlation $r$ is equal to 0.64 which indicates moderate to strong correlation, while the p-value is equal to $2.2^{-16}$. Since the p-value is small, the correlation is statistically significant.

\section{Recommendations}

This study offers the following recommendations:

a) The need to understand the causes of the declining trend in Tuvalu rainfall de-trended values could be a future research activity.

b) Box plot models can be used as an option to define drought.

c) De-trended values are excellent information in examining drought years for Tuvalu.

d) La Niña and negative SST in Tuvalu correspond with below normal rainfall a perfect drought predictors.

\section{Conclusion}

The study noted the complexities of drought as a natural climate phenomenon that can threaten ecosystems, economies and the livelihood of people in a small Pacific country like Tuvalu. The striking features of observed rainfall time series and de-trended rainfall time series from four rainfall stations all point toward declining rainfall trends. The frequency of drought varies between three and fourteen years, with a total of eight extreme droughts identified over the last 60 years. La Niña years were identified using ONI and MEI and matched with drought years in Tuvalu. An option in defining drought for Tuvalu is using box plot models and calculating long term medians as the threshold for normal or neutral rainfall. Drought can be defined as times when rainfall volumes fall $25 \%$ below the median, while extreme drought can be defined as $40 \%$ or more below the median. Finally, the correlations between SST (Nino 3.4) and de-trended rainfall values for all stations were moderate to strong and statistically significant.

\section{Acknowledgement}

This paper is part of the research for MSc thesis conducted by Luke Paeniu and supervised by Elisabeth Holland with statistical guidance provided by Cara Miller while editing was guided by Giulia Anderson. 
Citation: Paeniu L, Holland E, Miller C, Anderson G (2017) Rainfall Trends, Drought Frequency and La Niña in Tuvalu: A Small Equatorial Island State in the Pacific Ocean. J Environ Anal Toxicol 7: 501. doi: 10.4172/2161-0525.1000501

\section{References}

1. Wilhite DA (2000) Drought as a natural hazard: concepts and definitions.

2. Wilhite DA, Svoboda MD, Hayes MJ (2007) Understanding the complex impacts of drought: a key to enhancing drought mitigation and preparedness. Water Resources Management 21: 763-774.

3. Reig P, Shiao T, Gassert F (2013) Aqueduct Water Risk Framework. Working Paper. Washington, DC: World Resources Institute.

4. Patel NR, Chopra P, Dadhwal VK (2007) Analyzing spatial patterns of meteorological drought using standardized precipitation index. Meteorological Applications 14: 329-336.

5. Dai A (2011) Drought under global warming: a review. Wiley Interdisciplinary Reviews: Climate Change 2: 45-65.

6. NZ Meteorology Office (1943) Climatological notes South Pacific region: The climate of the Ellice Islands, New Zealand Meteorological Office.

7. Doberitz R, Flohn H, Schütte K (1967) Statistical investigations of the climatic anomalies of the equatorial Pacific. Univ. Meteorolog. Inst.; Dümmler in Komm.

8. Thompson CS (1987) The climate and weather of Tuvalu. New Zealand Meteorological Service, Wellington, New Zealand.
9. McLean RF, Holthus PF, Hosking PL, Woodroffe CD (1991) Tuvalu Land Resources Survey: Vaitupu.

10. McLean RF, Holthus PF, Woodroffe CD, Kelly J (1986) Tuvalu Land Resources Survey: Nukufetau. Island Report, p: 6.

11. McLean RF, Holthus PF, Hosking PL, Woodroffe CD (1991) Tuvalu Land Resources Survey: Nanumea. Auckland, New Zealand. FAO and UNDP, 1991.

12. McLean RF, Hosking PL (1992) Tuvalu Land Resources Survey: Funafuti.

13. Vavae $H$ (2008) A simple forecasting scheme for predicting low rainfalls in Funafuti, Tuvalu. Doctoral Dissertation, The University of Waikato.

14. Bardsley WE, Vavae H (2009) A simple graphical technique for conditional long range forecasting of below-average rainfall periods in the Tuvalu Islands, Western Pacific. Natural Resources Research 18: 277

15. Australian Bureau of Meteorology and CSIRO (2011) Climate Change in the Pacific: Scientific Assessment and New Research. Volume 1: Regional Overview. Volume 2: Country Reports. Australia.

16. Yu JY, Kao HY, Lee T, Kim ST (2011) Subsurface ocean temperature indices for Central-Pacific and Eastern-Pacific types of El Niño and La Niña events. Theoretical and Applied Climatology 103: 337-344.

17. Data C, Room M, Portal C (2000) Multivariate ENSO Index. esrl.noaa.gov. 